\title{
FUEL CYCLE SERVICES THE HEART OF NUCLEAR ENERGY
}

\author{
Soedyartomo Soentono \\ National Nuclear Energy Agency (BATAN) \\ Jl. Kuningan Barat, Mampang Prapatan, Jakarta 12710, Indonesia
}

\begin{abstract}
FUEL CYCLE SERVICES THE HEART OF NUCLEAR ENERGY. Fuel is essential for development whether for survival and or wealth creation purposes. In this century the utilization of fuels need to be improved although energy mix is still to be the most rational choice. The large amount utilization of un-renewable fossil has some disadvantages since its low energy content requires massive extraction, transport, and processing while emitting $\mathrm{CO}_{2}$ resulting degradation of the environment. In the mean time the advancement of nuclear science and technology has improved significantly the performance of nuclear power plant, management of radioactive waste, enhancement of proliferation resistance, and more economic competitiveness. Ever since the last decade of the last century the nuclear renaissance has taken place. This is also due to the fact that nuclear energy does not emit GHG. Although the nuclear fuel offers a virtually limitless source of economic energy, it is only so if the nuclear fuel is reprocessed and recycled. Consequently, the fuel cycle is to be even more of paramount important in the future. The infrastructure of the fuel cycle services worldwide has been adequately available. Various International Initiatives to access the fuel cycle services are also offered. However, it is required to put in place the International Arrangements to guaranty secured sustainable supply of services and its peaceful use. Relevant international cooperations are central for proceeding with the utilization of nuclear energy, while this advantageous nuclear energy utilization relies on the fuel cycle services. It is therefore concluded that the fuel cycle services are the heart of nuclear energy, and the international nuclear community should work together to maintain the availability of this nuclear fuel cycle services timely, sufficiently, and economically.
\end{abstract}

Keywords : Fuel Cycle, Nuclear Energy, Green House Gas Emission, NPP

\section{INTRODUCTION}

The advancement of science and technology has promoted fuel to a very important position. In rich industrial countries it is used for increasing and improving their industrial output, while in developing countries the fuel is needed for poverty alleviation, producing food, serving health care, and also for their growing industries. The need for fuel in this century is still unfortunately not merely for the improvement of the living standards, but even for bare necessities for growing population. The demand for energy is to increase $53 \%$ up to 2030 . The current energy per capita is $>8500 \mathrm{kWh} / \mathrm{y}$ in industrial countries but only about $<100$ to couple hundred $\mathrm{kWh} / \mathrm{y}$ in the developing countries. In the mean time there are 1.6 billion people without access to electricity, and 2.4 billion people rely on traditional biomass without access to modern energy sources. On the other hand, the fuel, especially the non-renewable ones is depleting fast and the price is volatile 
while its utilization also deteriorating the environment. Therefore, since the last century, people have tried to reduce, reuse, recycle, and recover the fuel as much as possible to conserve the natural resources and protect the environment. The new and renewable energy sources are more and more developed and cultivated to replace the fuel from non-renewable ones. One type of fuel was also progressively replaced by another one which requires less resources for their extraction, transport, and processing. Large amount of fossil utilization for generating process heat and or electricity for industry can easily be replaced by nuclear energy for power production. However, fossil has still various irreplaceable roles and uses in society. Thus, most countries have a mix energy policy covering non-renewable, new, and renewable energy sources with different composition depending on their unique situations relating to various factors, e.g. population and economic growths, life-style, country's potency on domestic energy sources, etc to secure the sustainable energy supply. It is desired that the advancement of science and technology is to continue enhancing conservation, diversification, and intensification of fuel while improving the deteriorated environment, especially due to $\mathrm{CO} 2$ emission giving rise to global warming that has become much more pronounce in recent years.

Table 1. Specific Energy Content of Various fuel

\begin{tabular}{|l|l|}
\hline Type of Fuel & GJ / ton \\
\hline Wood & $16-18$ \\
\hline Coal & $23-30$ \\
\hline Oil & $42-44$ \\
\hline Gas & 50 \\
\hline U ore, refined and fission to & \\
\hline$\sim 1 \%$ in a thermal reactor & 800 \\
\hline$\sim 60 \%$ in a fast reactor & 48,000 \\
\hline
\end{tabular}

Note: Natural U contains $99.283 \%$ 238U, $0.711 \% 235 \mathrm{U}$ and $0.0054 \% 234 \mathrm{U}$. In the nuclear power plant (NPP), $\mathrm{U}$ and to a lesser extent $\mathrm{Th}$ and $\mathrm{Pu}$ (not occurred naturally, but emerged as a product of transmutation of $U$ in the NPP) are used as fuels. Supplies of U, like any other fuel supply, will not last forever. The development of fast reactor will enable at least fifty times as much energy to be extracted from U. A breeder reactor can be used to produce more fissile material by neutron capture than is consumed by fission. A fast reactor using $239 \mathrm{Pu}$ as the fuel and $238 \mathrm{U}$ as the fertile species can act as a power breeder, generating power and at the same time, producing more $239 \mathrm{Pu}$ than is consumed. An analogous fast power breeder reactor is possible with $233 \mathrm{U}$ and $232 \mathrm{Th}$ as the fissile and fertile nuclides respectively. Thus, unlike any other fuel, nuclear fuel offers the prospect of virtually limitless source of economic energy if the nuclear fuel is reprocessed and recycled 


\section{Atmospheric $\mathrm{CO}_{2}$ Concentration over the Last Millennium}

Summary for Policy Makers - A report of Working Group I of the Intergovernmental Panel on Climate Change - IPCC Third Assessment Report - Climate Change 2001 (Figure 1)

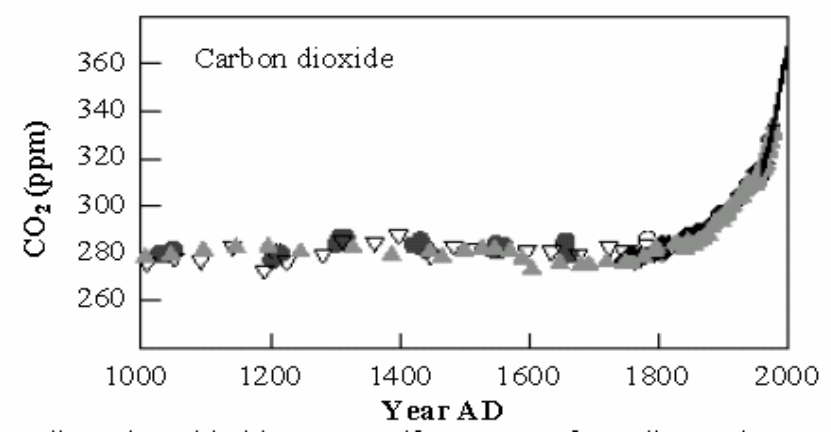

Figure 1. Atmospheric $\mathrm{CO}_{2}$ concentration over the last millennium (Source:[1]).

\section{Situation in the World - Climatic Change}

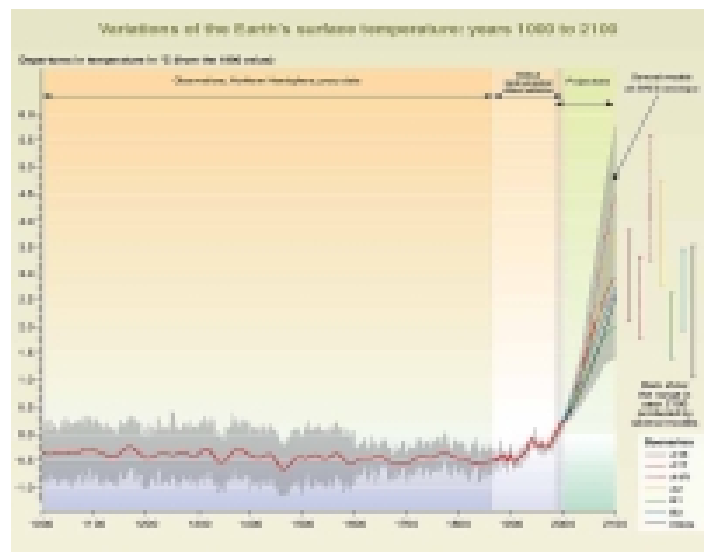

Figure 2. Variation of the Earth's surface temperature years 1000 to 2100.

From year 1000 to 1860 variations in average surface temperature of the Northern Hemisphere are shown reconstructed from proxy data (tree rings, corals, ice cores, and historical records). The line shows the 50-year average, the grey region the $95 \%$ confidence limit in the annual data [2]. 
Green House Gas Emissions from Electricity Generation by Various Sources

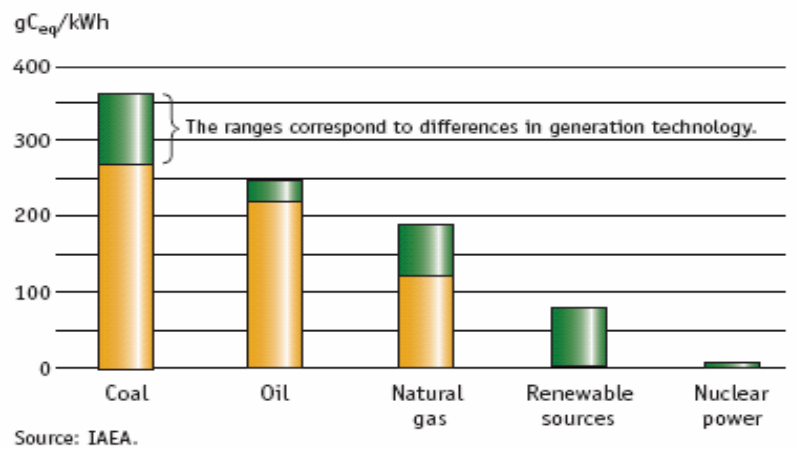

Figure 3. Green house gas from electricity generation by different sources [3].

\section{Why Nuclear Power?}

\section{< Renewable Energy >}

Introducing solar, wind and other new energy sources is also an extremely efficient means of reducing $\mathrm{CO}_{2}$ emissions. At present, however, these new energy sources still have issues of supply stability (energy cannot be generated on rainy days or when the wind does not blow), economic feasibility, etc. Under the present conditions, the power output of systems using natural energy such as solar power generation and wind power generation is prone to fluctuation, so backup power sources are essential.

\section{Comparison of Each Type of Electricity Generation}
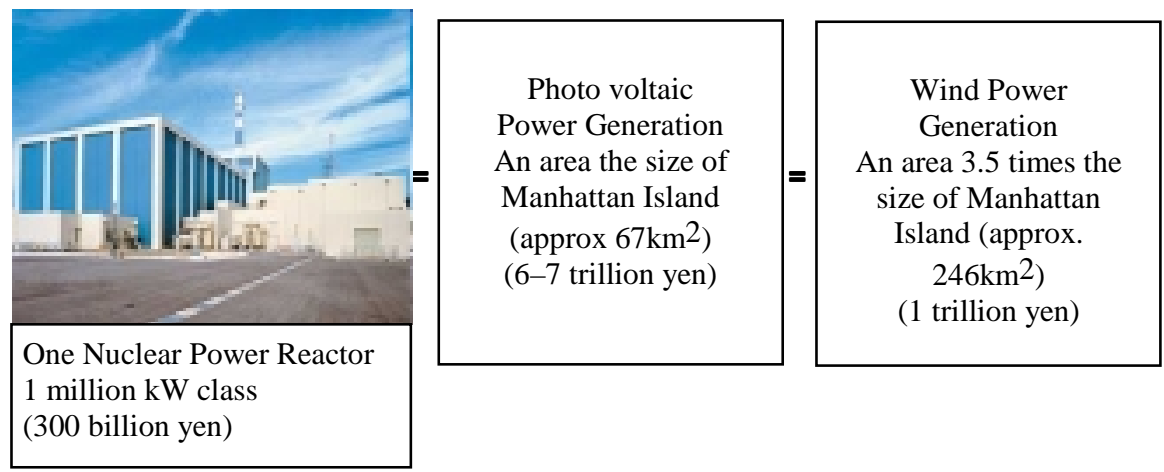

Figure 4. Comparison of Each Type of Electricity Generation. 


\section{THE ROLE OF NUCLEAR FUEL CYCLE}

The resources of $235 \mathrm{U}$, the only fissile material existing in nature, are limited. There will be a time when all the $235 \mathrm{U}$ is exhausted. In this situation, further use of the remaining $238 \mathrm{U}$ and $232 \mathrm{Th}$ will then depend on the use of $239 \mathrm{Pu}$ or $233 \mathrm{U}$ to maintain the fission chain. At present, significant amount of $239 \mathrm{Pu}$ has been produced by reactors that have been in use for couple decade. Reprocessing of spent fuels to recover the $\mathrm{U}$ and $\mathrm{Pu}$ is of paramount important.

The nuclear fuel cycle may be defined as the path followed by the reactor fuel in its various stages which involves the production of fuel material from ore, fabrication of fuel elements, reprocessing of the irradiated fuel for recovering the fissile and fertile elements, and the disposal of the radioactive wastes.

Considering the nuclear renaissance that has taken place about the last decade of the last century following the significant enhancement on the safety (and security) of the reactor, radioactive wastes management, proliferation resistance, and more economic competitiveness as well as more severe global warming due to the use of various fuels especially of fossil ones, the role of nuclear fuel cycle is to continue being even more important. Further more, the advancement of reactor engineering is encouraging that the NPP will soon be available for cogeneration, producing electricity and process heat for hydrogen production, desalination, coal gasification and liquefaction, and EOR, giving rise to more demand for nuclear fuel.

As any other technology, some stages of nuclear fuel cycle are sensitive for dual purposes. It is therefore a must that international arrangements are in place for any country needs to have access to nuclear fuel cycle services. International arrangements and international co-operations are needed to suffice the needs for security of nuclear fuel sustainable supply leading to economic competitiveness, and peaceful use.

The international nuclear community should work together on the nuclear fuel cycle activities to establish the enhancement of safe, secure, sustainable, more economic and peaceful operation of nuclear energy to contribute the MDGs 


\section{FUEL CYCLE}

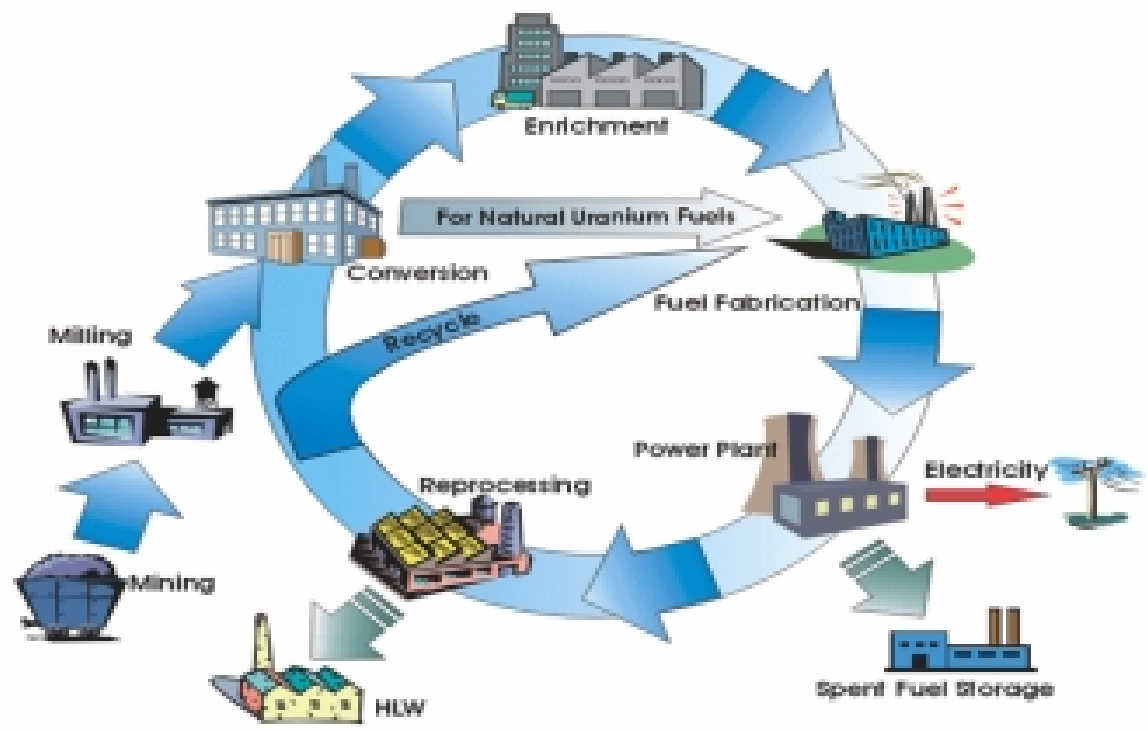

Figure 5. Fuel Cycle.

For nuclear energy to be sustainable as a global source of emission free energy, the reactor fuel cycle must also remain sustainable [4].

Table 2. Major uranium conversion facilities worldwide.

Coulntry

Conado

Frange

Russian Federtion

United kngdon United States
Site (s)

Blind River and Font Hope, Dntano

Malues: Pierelatte

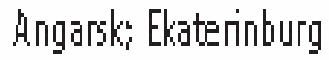

Springfields, Lancoshire

Metropolis, Illinois 
Table 3. Major uranium enrichment facilities worldwide.

\begin{tabular}{lll} 
Country & Site(s) & Technology \\
China & Lanzhou & Centrifuge \\
& Shaanxi & Centrifuge \\
Franoe & Tricastin & Gaseous diffusion \\
Germany & Gronau & Centrifuge \\
Japan & Rokkasho-mura & Centrifuge \\
Netherlands & Almelo & Centrifuge \\
Russia & Angarsk & Centrifuge \\
& Ekaterinburg & Centrifuge \\
& Krasnoyarsk & Centrifuge \\
& Sewersk & Centrifuge \\
United Kingdom & Capenhurst & Centrifuge \\
United States & Paducah & Gaseous diffusion \\
\hline
\end{tabular}

1. Under mistruction.

Table 4. Commercial spent nuclear fuel reprocessing plants worldwide [3].

\begin{tabular}{llll}
\hline Country & Facility/location & $\begin{array}{l}\text { Year of } \\
\text { commissioning }\end{array}$ & Fuel type \\
China & Diwopu (Ganzu) & 2002 & LWR \\
France & La Hague & 1976 & LWR \\
India & Kalpakkam & 1998 & PHWR \\
& Tarapur & 1974 & PHWR \\
Japan & Rokkasho-mura & 2005 (planned) & LWR \\
& Tokai-mura & 1977 & LWR, ATR \\
Russian Federation & Tcheliabinsk-65 Mayak & 1984 & WWER \\
UK & B205/Sellafield & 1964 & Magnox GCR \\
& Thom/Sellafield & 1994 & LWR, AGR \\
\hline
\end{tabular}

Source: Nuclear Energy Today, 2003 


\section{NPP PROSPECT WORLDWIDE}
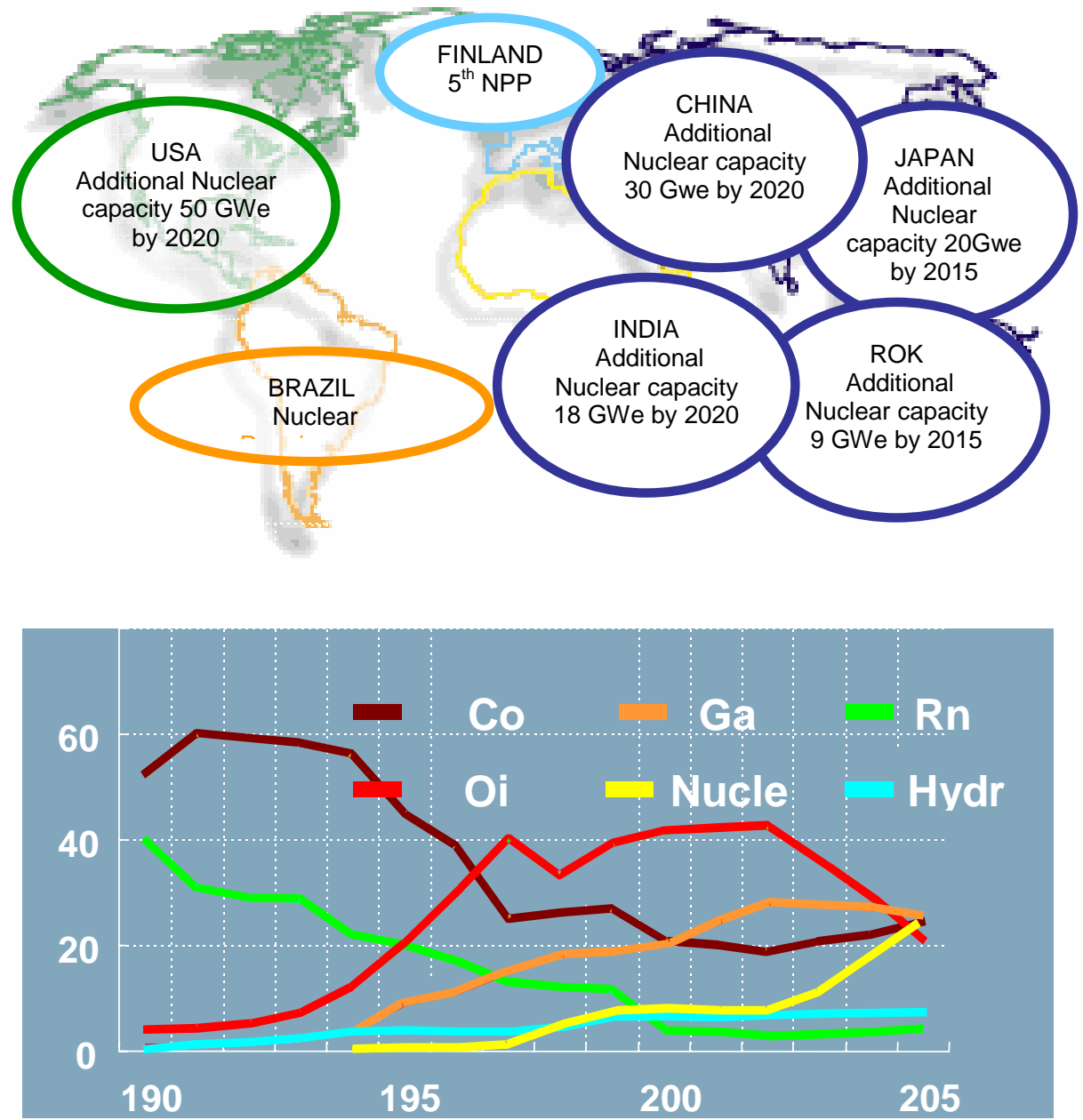

Figure 6. NPP Prospects worldwide [5].

\section{ISSUE ON NON PEACEFUL USES OF FUEL CYCLE}

Enrichment \& Reprocessing may be diverted to produce weapon grade ${ }^{235} \mathrm{U}$ and ${ }^{239} \mathrm{Pu}$. Therefore "integrated safeguard" (Comprehensive Safeguard Agreement and Additional Protocol) is required.The radioactive substance may also be diverted to be "dirty bomb" so besides SSAC and RAIS, "physical protection" is required 


\section{INTERNATIONAL NUCLEAR ARRANGEMENTS RELATING TO FUEL CYCLE SERVICES}

The commercial fuel cycle services are available currently worldwide. This is indeed important to suffice the increasing demands to supply fuel for increasing number of NPP. Anticipation about the timely adequate capacities is needed due to the fact that the nuclear renaissance has taken place for quite sometime while construction of new NPPs is to take place more in Asian countries. Some countries are introducing NPP for the first time which means that these countries are most likely to rely on international fuel cycle services for their NPP operation for sometime in the future. Consequently, the activities on the fuel cycle services are to grow in a higher rate.

The development of nuclear power programmed has been typified by high degree of international cooperation and regulation. Many international agencies, treaties, and conventions exist for control and regulatory purposes, as well as for technical information exchanges. This is to guaranty that the programmed is to be successful, safe, secure, peaceful, sustainable and more economic gain. The activities in this matter are also to increase accordingly.

It is also worth to note that significant infrastructure has to be already in place in the country when the construction of the first NPP commence, e.g. legal, regulation, candidate site conforming the safety requirements, electrical grid with the capacity that big enough to accept the NPP as a base load generating plant, etc.

Table 5. International Nuclear Arrangements Relating to Fuel Cycle Services

\begin{tabular}{|l|l|l|}
\hline NO. & $\begin{array}{l}\text { INTERNATIONAL NUCLEAR TREATIES, } \\
\text { CONVENTIONS, AND REGULATIONS }\end{array}$ & \multicolumn{1}{|c|}{ Examples of Indonesian Status } \\
\hline 1. & $\begin{array}{l}\text { LS Non-Proliferation Treaty (NPT) } \\
\text { Safeguard Agreement with IAEA }\end{array}$ & $\begin{array}{l}\text { Ratified : Act No.8 / 1978 Signed } \\
\text { Valid) } \\
\text { Ratified : Act No.8 / 1978 Signed } \\
\text { (Valid) }\end{array}$ \\
\hline 2. & $\begin{array}{l}\text { Convention on Physical Protection of Nuclear } \\
\text { Material and its amendment }\end{array}$ & Ratified : President Decree No.49 / 1986 \\
\hline 3. & $\begin{array}{l}\text { Convention on Early Notification of a Nuclear } \\
\text { Accident }\end{array}$ & Ratified : President Decree No.81 / 1993 \\
\hline 4. & $\begin{array}{l}\text { Convention on Assistance in the Case of a } \\
\text { Nuclear Accident or Radiological Emergency }\end{array}$ & Ratified : President Decree No.82 / 1993 \\
\hline 5. & $\begin{array}{l}\text { Treaty on the South East Asia Nuclear Weapon } \\
\text { Free Zone }\end{array}$ & Ratified : UU No.9/1997 \\
\hline 6. & $\begin{array}{l}\text { Convention on Nuclear Safety } \\
\text { Ratified : President Decree No.106 / } \\
\text { 2001 }\end{array}$ \\
\hline 7. & $\begin{array}{l}\text { Convention on Supplementary Compensation for } \\
\text { Nuclear Damage }\end{array}$ & Signed 1997 \\
\hline 8. & Comprehensive Nuclear Test-Ban Treaty (CTBT) & Signed 1996 \\
\hline 9. & $\begin{array}{l}\text { Joint Convention on the Safety of Spent Fuel } \\
\text { Management and the Safety of Radioactive } \\
\text { Waste Management }\end{array}$ & Signed (1997) \\
\hline 10. & Protocol to Amend the Vienna Convention & Signed (1997) \\
\hline 11. & Bilateral Cooperation and Supply Agreement (s) & Signed 1997 \\
\hline
\end{tabular}




\section{INTERNATIONAL INITIATIVES TO ACCESS THE FUEL CYCLE SERVICES}

1. MNA (Multilateral Approach to the Nuclear Fuel Cycle ) Initiative of the Director General of the IAEA in 2003 and reported by the Expert Group February 2005

2. Developing Global Nuclear Infrastructure. Initiative by the President of the Russian Federation, 25 January 2006

3. GNEP (The Global Nuclear Energy Partnership) USA President Initiative, February 20064.

4. RANF (Concept for a Multilateral Mechanism for Reliable Access to Nuclear Fuel), initiative of French, Germany, the Netherlands, USA, Russia, and UK-May 2006.

5. NTI (Nuclear Threat Initiative), initiative of a Non-government institute of Washington DC., communicated to the DG of the IAEA September 2006

\section{CONCLUSION}

The energy development in the world shows increasing demands due to growing population and the need to pursuit people welfare whether for survival and or increasing the standard of living. The massive demand for fuel had been responded by massive use of non-renewable energy resources with low energy content that deteriorated the environment. Due to its advantages, the nuclear fuels is replacing significant amount of other fuels to suffice the higher growing energy demand while protecting and recovering the environment. However the natural fissile material is also limited and needed to be recycled while producing artificial fissile materials to sustain the nuclear chain and to offer virtually limitless source of economic energy. This is only true if the nuclear fuel cycle is available with the adequate capacity timely and the services are accessible through international arrangements to realize sustainable and peaceful use of the nuclear fuels.

The international nuclear community has led all necessary activities, and developed significant infrastructure, e.g. international arrangements for NPP and fuel cycle services.

The international cooperation, i.e. multilateral, regional, and bilateral with developed and experience countries are needed to enable developing countries to pursuit safe, secure, and peaceful introduction as well as sustainable operation of the NPP and its economic competitiveness.

The long term cooperation is also expected to be committed to give rise the enhancement of domestic industry to be reliable, safe, and peaceful nuclear industries enjoying the state of the art technology from advanced countries while contributing also to the security of fuel cycle services. 


\section{REFERENCES}

1. Source, "http:www.ipc.ch/spm22-01.pdf".

2. IPCC, "Third Assessment Report - Climate Change", (2001).

3. Nuclear Energy Today, NEA-OECD, (2003)

4. DG-IAEA, Scientific Forum, (2004).

5. Total Final Elf, (2000). 